\title{
8
}
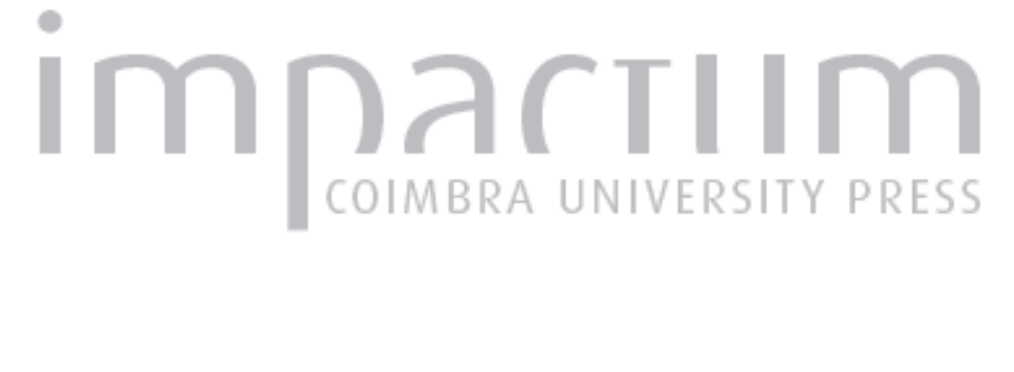

\section{Caracterização química das produções de ânforas do Vale do Tejo: II - Quinta do} Rouxinol

\author{
Autor(es): $\quad$ Cabral, J. M. Peixoto; Gouveia, M. Ángela; Morgado, Isabel \\ Publicado por: Imprensa da Universidade de Coimbra \\ URL \\ persistente: \\ URI:http://hdl.handle.net/10316.2/45485 \\ DOI: \\ DOI:https://dx.doi.org/10.14195/1647-8657_32_33_11 \\ Accessed : $\quad$ 26-Apr-2023 13:46:24
}

A navegação consulta e descarregamento dos títulos inseridos nas Bibliotecas Digitais UC Digitalis, UC Pombalina e UC Impactum, pressupõem a aceitação plena e sem reservas dos Termos e Condições de Uso destas Bibliotecas Digitais, disponíveis em https://digitalis.uc.pt/pt-pt/termos.

Conforme exposto nos referidos Termos e Condições de Uso, o descarregamento de títulos de acesso restrito requer uma licença válida de autorização devendo o utilizador aceder ao(s) documento(s) a partir de um endereço de IP da instituição detentora da supramencionada licença.

Ao utilizador é apenas permitido o descarregamento para uso pessoal, pelo que o emprego do(s) título(s) descarregado(s) para outro fim, designadamente comercial, carece de autorização do respetivo autor ou editor da obra.

Na medida em que todas as obras da UC Digitalis se encontram protegidas pelo Código do Direito de Autor e Direitos Conexos e demais legislação aplicável, toda a cópia, parcial ou total, deste documento, nos casos em que é legalmente admitida, deverá conter ou fazer-se acompanhar por este aviso.

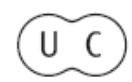




\section{UNIVERSIDADE DE COIMBRA \\ FACULDADE DE LETRAS}

\section{CONIMBRIGA}

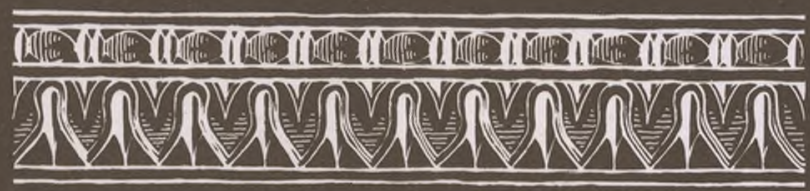

VOLUMES XXXII-XXXIII-1993/94 


\title{
J. M. Peixoto Cabral, M. Ángela Gouveia, Isabel Morgado Investigadores do Departamento de Química do ICEN, INETI
}

\author{
CARACTERIZAÇÃO QUÍMICA DAS PRODUÇÕES DE ÂNFORAS \\ DO VALE DO TEJO: II - QUINTA DO ROUXINOL \\ «Conimbriga» XXXII-XXXIII (1993-1994), p. 191-200
}

RESUmo: Analisaram-se, por activação com neutrões térmicos, 25 amostras de ânforas recolhidas na Quinta do Rouxinol (Seixal), de tipo Almagro 50, Almagro 5 le e Dressei 28. Os resultados obtidos foram tratados por métodos de análise estatística multivariada. Contrariamente ao que se apurara no caso das ânforas de Porto dos Cacos (Alcochete), não se verificou nenhuma relação entre o agrupamento das 25 ânforas analisadas, efectuado por meio destes métodos, e o agrupamento feito com base nas suas características tipológicas. Verificou-se, porém, que, do ponto de vista da composição química das pastas cerâmicas, todas as ânforas da Quinta do Rouxinol se diferenciam das ânforas de Porto dos Cacos, qualquer que seja o tipo.

ABSTRACT: Neutron activation analysis was used to characterize Roman workshops producing amphorae of the Almagro 50, Almagro 51c and Dressel 28 types, in the area of the left bank of the Tagus (Portugal), namely the Quinta do Rouxinol (Seixal) workshop. The results showed that this method of analysis makes it possible to distinguish local amphora production from those of Porto dos Cacos (Herdade de Rio Frio) workshop, situated in the same area. 
(Página deixada propositadamente em branco) 


\section{CARACTERIZAÇÃO QUÍMICA DAS PRODUÇÕES DE ÂNFORAS DO VALE DO TEJO: II - QUINTA DO ROUXINOL}

\section{Introdução}

É sabido que os centros produtores de preparados piscícolas e de outros produtos alimentares, a operar na região do Vale do Tejo, na época romana, eram abastecidos, no que se refere ao vasilhame, por diversas oficinas (AMARO, 1990a; RAPOSO e DUARTE, 1992), desigadamente (Fig. 1) as localizadas em Porto dos Cacos - Herdade de Rio Frio, próxima de Alcochete (RAPOSO, 1990), na Quinta do Rouxinol - Seixal (DuARTE, 1990), e na Quinta da Garrocheira - Benavente (AMARO, 1990b).

A fim de estudar o regime de funcionamento de tais oficinas, relativamente ao abastecimento de matérias-primas, iniciou-se em 1991 um projecto de caracterização química das pastas cerâmicas das respectivas produções anfóricas, o qual principiou pela análise de um conjunto de mais de uma centena de amostras recolhidas no complexo industrial de Porto dos Cacos, em particular de ânforas dos tipos Dressel 14, Dressel 30, Almagro 50 e Almagro 51c. Os resultados obtidos nesta primeira fase mostraram que o agrupamento das ânforas caracterizadas daquela maneira, realizado fazendo uso de métodos de análise estatística multivariada, concorda excelentemente com o agrupamento feito pela equipa de arqueólogos associados ao estudo do lugar, baseado nas suas características tipológicas (CABRAL et allii, 1994).

$\mathrm{O}$ presente trabalho, que constitui uma parte preliminar da segunda fase do referido projecto, tem a ver, sobretudo, com as produções de ânforas da oficina da Quinta do Rouxinol. 


\section{Material}

Foram consideradas 25 amostras de ânforas, das quais, de acordo com o exame tipologico efectuado pela equipa de arqueólogos atrás citada (RAPOSO, 1991), treze eram da forma Almagro 51c, onze da forma Almagro 50 e uma da forma Dressel 28. No Quadro I indicam-se os locais onde elas foram recolhidas, bem como os símbolos por que foram designadas no laboratório.

Quadro I - Amostras consideradas

\begin{tabular}{|c|c|c|c|c|}
\hline $\begin{array}{l}\text { DESIGNAÇÃO } \\
\text { LABORATORIAL }\end{array}$ & ÁREA & PLANO & CAMADA & LORMA \\
\hline $\mathrm{F} 1$ & Forno 1 & - & 2 & Almagro 51c \\
\hline $\mathrm{F} 2$ & $»$ & & 7 & $\gg$ \\
\hline Gl & $»$ & & 7 & Almagro 50 \\
\hline $\mathrm{G} 2$ & $»$ & & 11 & $»$ \\
\hline $\mathrm{Hl}$ & Forno 2 & 11 & 48 & Almagro Sic \\
\hline $\mathrm{H} 2$ & $\gg$ & 12 & 49 & » \\
\hline $\mathrm{H} 3$ & $»$ & 14 & 195 & $\gg$ \\
\hline 11 & $»$ & 11 & 48 & Almagro 50 \\
\hline KI & $»$ & 14 & 195 & Dressel 28 \\
\hline LI & Quadrado B.10 & 6 & $61-B$ & Almagro 51c \\
\hline L2 & $»$ & 7 & 62 & $\gg$ \\
\hline L3 & $»$ & 8 & 64 & $»$ \\
\hline L4 & $\gg$ & 9 & 68 & $\gg$ \\
\hline L5 & $»$ & 10 & 72 & $»$ \\
\hline L6 & $»$ & 11 & 91 & $»$ \\
\hline L7 & $»$ & 12 & 95 & $»$ \\
\hline L8 & $»$ & 13 & 98 & $»$ \\
\hline Ml & $»$ & 6 & $61-B$ & Almagro 50 \\
\hline M2 & $»$ & 7 & 62 & $»$ \\
\hline M3 & $»$ & 8 & 64 & $»$ \\
\hline M4 & $»$ & 9 & 68 & $»$ \\
\hline M5 & $»$ & 10 & 72 & $»$ \\
\hline M6 & $»$ & 11 & 91 & $»$ \\
\hline M7 & $»$ & 12 & 95 & $»$ \\
\hline M8 & $»$ & 13 & 98 & $»$ \\
\hline
\end{tabular}

Conimbriga, 32-33 (1993-1994), 191-200 


\section{Métodos}

A caracterização química das amostras foi feita recorrendo ao método de análise por activação com neutrões térmicos, de acordo com a técnica empregada anteriormente pelos autores (CABRAL et allii, 1994).

Em cada amostra determinaram-se as concentrações de 27 elementos químicos, três dos quais - $\mathrm{Na}, \mathrm{Fe}$ e $\mathrm{K}$ - são constituintes principais das pastas cerâmicas, sendo os 24 restantes elementos vestigiais $(*)$, nomeadamente os seguintes: $\mathrm{Sc}, \mathrm{Cr}, \mathrm{Mn}, \mathrm{Co}, \mathrm{Zn}, \mathrm{As}, \mathrm{Rb}, \mathrm{Sb}$, Cs, Ba, La, Ce, Nd, Sm, Eu, Tb, Dy, Tm, Yb, Lu, Hf, Ta, Th e U.

O tratamento matemático dos resultados obtidos nos ensaios de caracterização química foi efectuado usando métodos de análise estatística multivariada, em particular métodos de análise de grupos, os quais foram aplicados a matrizes de semelhanças, cujos valores se determinaram para cada par de ânforas empregando dois tipos de coeficientes de semelhança - a distância euclidiana média e o coeficiente de correlação de Pearson (CABRAL, 1977). A determinação de ambos os coeficientes foi feita tomando por base os logaritmos dos resultados daqueles ensaios, expressos em ppm.

Para realizar os cálculos, na análise de grupos, recorreu-se ao sistema de programas NTSYS-pc (ROHLF, 1992). Para testar a significância dos grupos obtidos, fez-se uso do programa ADCORR (SAYRE, 1976).

\section{Resultados e discussão}

Os resultados das análises químicas encontram-se no Anexo 1.

Na Fig. 2 e na Fig. 3 mostram-se os dendrogramas representativos dos agrupamentos das 25 ânforas da Quinta do Rouxinol, obtidos aplicando o método UPGMA às duas matrizes de semelhanças calculadas - a matriz de distâncias e a matriz de coeficientes de correlação. O grau de ajustamento desses dendrogramas às correspondentes matrizes de semelhanças foi medido determinando, em cada caso, o

(*) Elementos presentes em percentagens inferiores a $0,1 \%$, ou seja, em concentrações menores que 1000 ppm (partes por milhão). 
coeficiente de correlação cofenética (CABRAL, 1977). Obtiveram-se os valores de 0,82 e 0,85 respectivamente, o que representa um grau muito satisfatório de ajustamento.

Na Fig. 4 e na Fig. 5 apresentam-se os dendrogramas obtidos usando o mesmo método (UPGMA) aplicado à matriz de distâncias e à matriz de coeficientes de correlação, respectivamente, calculadas agora considerando não só as 25 amostras de ânforas da Quinta do Rouxinol, mas também as 111 mostras de ânforas de Porto dos Cacos, cuja caracterização química tinha sido feita num trabalho anterior (CABRAL et alii, 1994). Para estes dendrogramas, os coeficientes de correlação cofenética calculados foram 0,75 e 0,72 respectivamente, o que atesta a razoável fidelidade de ambas as representações.

Como se pode ver nas Figs. 2 e 3, no caso das ânforas produzidas na Quinta do Rouxinol, parece não haver nenhuma relação entre os agrupamentos efectuados com base em atributos de natureza química e o agrupamento feito baseado nas suas características tipológicas, ao contrário do que se verificara para as ânforas de Porto dos Cacos. No entanto, atendendo a que o número de amostras analisadas da Quinta do Rouxinol foi muito pequeno, considera-se aconselhável esperar pela análise de mais amostras para se inferir com segurança sobre a inexistência de tal relação. Por outro lado, parece não haver nenhuma diferença significativa entre as composições químicas das pastas das ânforas fabricadas no forno 1 e as composições químicas das pastas das ânforas fabricadas no forno 2. Contudo, embora isto seja de esperar, também aqui será prudente aguardar pela análise de mais amostras, pelo mesmo motivo.

Por sua vez, as Figs. 4 e 5 mostram que, exceptuando F2, H2, K1, L5, M3, M5 e M6, a maioria das ânforas da Quinta do Rouxinol, quaisquer que sejam as suas formas, se aglomera num só grupo, discernível, quanto à composição química, dos grupos de ânforas produzidas em Porto dos Cacos. Infelizmente, porém, não foi possível calcular a probabilidade de cada uma das ânforas agora analisadas pertencer efectivamente ao grupo da Quinta do Rouxinol, quando ele é tomado como grupo básico nos testes de significância, em virtude de o número de amostras (25) não ser suficientemente grande em relação ao número de atributos (os 27 elementos químicos determinados) utilizados na sua caracterização.

Foi possível, no entanto, calcular a probabilidade de cada uma das 25 amostras poder pertencer aos grupos de ânforas Dressel 14, Dressel 
30 e Almagro 51c de Porto dos Cacos, que se distinguem uns dos outros não só tipologicamente como ainda no tocante à composição química (CABRAL et olii, 1994), quando cada um desses grupos é tomado como grupo básico nos testes de significância. Em todos estes cálculos verificou-se que tal probabilidade era zero, o que mostra, embora indirectamente, que as ânforas da Quinta do Rouxinol devem formar, de facto, um grupo diferenciável dos grupos de ânforas de Porto dos Cacos, do ponto de vista da composição química das respectivas pastas cerâmicas.

Assim, tudo leva a crer que a caracterização química das pastas, com auxílio dos métodos utilizados neste trabalho e no trabalho anterior sobre os materiais anfóricos de Porto dos Cacos, poderá constituir um processo seguro de determinar a proveniência de ânforas fabricadas em oficinas do Vale do Tejo e, consequentemente, de estudar com maior rigor o comércio de alguns produtos alimentares preparados em Portugal e transportados nesses contentores.

\section{BIBLIOGRAFIA}

AMaro, C. (1990a). Ocupação romana da margem sul do estuário do Tejo: um (des)alinhar de ideias, in A. Alarcão e F. Mayet (eds.), Anforas Lusitanas: tipologia, produção, comércio. Museu Monográfico de Conímbriga / Diffusion E. de Boccard, pp. 71-85.

Amaro, C. (1990b). Olaria romana da Garrocheira, Benavente, in A. Alarcão e F. Mayet (eds), Anforas Lusitanas: tipologia, produção, comércio. Museu Monográfico de Conímbriga / Diffusion E. de Boccard, pp. 87-95.

CABral, J. M. P. (1977). Caracterização de cerâmicas arqueológicas mediante análise por activação com neutrões térmicos: classificação das cerâmicas por métodos de taxonomia numérica, Conímbriga, XVI, pp. 103-137.

CABRAL, J. M. P. (1990). Determinação da proveniência de ânforas mediante a análise química da cerâmica, in A. Alarcão e F. Mayet (eds.), Ânforas Lusitanas: tipologia, produção, comércio. Museu Monográfico de Conímbriga / Diffusion E. de Boccard, pp.273-288.

Cabral, J. M. P.; Gouveia, M. A.; Morgado, I. (1995). Caracterização química das produções de ânforas do Vale do Tejo: I - Porto dos Cacos, in Actas das l.as Jornadas sobre a Romanização dos Estuários do Tejo e do Sado, Publicações Dom Quixote, no prelo.

Duarte, A. L. C. (1990). Quinta do Rouxinol: a produção de ânforas no Vale do Tejo, in A. Alarcão e F. Mayet (eds.), Ânforas Lusitanas: tipologia, produção, comércio. Museu Monográfico de Conímbriga / Diffusion E. de Boccard, pp. 96-115. 
Raposo, J. M. C. (1990). Porto dos Cacos: uma oficina de produção de ânforas romanas no Vale do Tejo, in A. Alarcão e F. Mayet (eds.), Anforas Lusitanas: tipologia, produção, comércio. Museu Monográfico de Conímbriga / Diffusion E.de Boccard, pp. 117-151.

Raposo, J. M. C. (1991). Comunicação privada.

Raposo, J. M. C.; Duarte, A. L. C. (1992). Ânforas Lusitanas: los alfares del Tajo, Revista de Arqueologia, XII, N. ${ }^{\circ}$ 134, pp. 36-45.

RoHLF, F. J. (1992). NTSYS-pc: Numerical Taxonomy and Multivariate Analysis System, Version 1. 70, Exeter Software, Setauket, New York.

SAYRE, V. E. (1976). Brookhaven procedures for statistical analyses of multivariate archaeometric data, Brookhaven National Laboratory, BNL-21693. 
ANEXO 1 - Resultados da análise por activação com neutrões

\begin{tabular}{|c|c|c|c|c|c|c|c|c|c|c|c|c|c|}
\hline & F1 & F2 & Gl & G2 & Hl & $\mathrm{H} 2$ & H3 & 11 & K1 & LI & L2 & L3 & L4 \\
\hline $\mathrm{Na}_{2} \mathrm{O} \%$ & 0,35 & 0,97 & 0,81 & 0,62 & 0,46 & 0,52 & 0,63 & 0,64 & 0,38 & 0,37 & 0,43 & 0,62 & 0,47 \\
\hline $\mathrm{K}_{2} 0 \%$ & 3,06 & 3,37 & 4,46 & 3,64 & 3,18 & 3,69 & 4,05 & 3,57 & 3,83 & 3,38 & 3,32 & 3,36 & 3,30 \\
\hline $\mathrm{Fe}_{2} \mathrm{O}_{3} \%$ & 6,62 & 5,58 & 6,99 & 6,19 & 6,58 & 6,39 & 6,67 & 6,86 & 5,21 & 6,64 & 5,17 & 6,24 & 4,87 \\
\hline Sc ppm & 12,7 & 13,7 & 14,9 & 14,5 & 13,4 & 14,2 & 14,5 & 15,2 & 12,7 & 15,2 & 12,9 & 13,7 & 12,4 \\
\hline Cr ppm & 61,3 & 62,5 & 68,3 & 65,1 & 65,5 & 74,8 & 72,7 & 69,4 & 53,3 & 70,5 & 61,4 & 66,0 & 59,5 \\
\hline $\mathrm{Mn} \mathrm{ppm}$ & 152 & 169 & 188 & 211 & 150 & 205 & 227 & 217 & 192 & 193 & 180 & 235 & 141 \\
\hline $\mathrm{CO}$ ppm & 6,66 & 8,28 & 9,26 & 8,44 & 6,08 & 9,08 & 8,54 & 8,20 & 6,64 & 7,97 & 7,78 & 10,20 & 6,80 \\
\hline Zn ppm & 69,5 & 77,4 & 91,7 & 87,8 & 67,6 & 85,2 & 94,7 & 84,7 & 67,6 & 82,5 & 75,2 & 88,6 & 70,2 \\
\hline As ppm & 9,12 & 2,32 & 8,96 & 8,28 & 5,44 & 3,27 & 7,56 & 6,26 & 2,42 & 7,61 & 11,90 & 9,51 & 11,30 \\
\hline $\mathrm{Rb}$ ppm & 187 & 188 & 243 & 242 & 203 & 222 & 234 & 233 & 205 & 227 & 192 & 197 & 185 \\
\hline $\mathrm{Sb} \mathrm{ppm}$ & 0,95 & 0,72 & 0,96 & 0,93 & 0,73 & 0,90 & 0,96 & 1,08 & 0,75 & 0,95 & 0,83 & 0,82 & 0,66 \\
\hline Cs ppm & 13,4 & 8,5 & 15,2 & 15,5 & 15,4 & 15,9 & 15,1 & 16,1 & 14,8 & 16,3 & 12,4 & 14,2 & 12,5 \\
\hline Ba ppm & 436 & 1510 & 625 & 457 & 468 & 453 & 549 & 439 & 432 & 444 & 423 & 539 & 380 \\
\hline La ppm & 33,5 & 40,8 & 40,1 & 43,6 & 34,9 & 44,5 & 40,5 & 47,0 & 42,9 & 45,5 & 37,8 & 46,0 & 36,9 \\
\hline Ce ppm & 63,8 & 83,8 & 79,0 & 84,7 & 67,0 & 89,2 & 79,1 & 94,0 & 82,7 & 87,3 & 77,4 & 91,5 & 71,9 \\
\hline $\mathrm{Nd} p \mathrm{pm}$ & 30,3 & 39,2 & 36,2 & 39,6 & 32,4 & 42,7 & 38,7 & 48,3 & 38,7 & 46,3 & 37,1 & 44,7 & 34,9 \\
\hline Sm ppm & 5,76 & 7,34 & 7,14 & 7,87 & 5,94 & 8,19 & 7,51 & 9,21 & 7,27 & 8,96 & 7,82 & 8,93 & 6,85 \\
\hline Eu ppm & 0,97 & 1,34 & 1,28 & 1,30 & 1,07 & 1,39 & 1,38 & 1,58 & 1,20 & 1,71 & 1,38 & 1,45 & 1,12 \\
\hline Tb ppm & 0,82 & 1,03 & 1,01 & 1,02 & 0,82 & 0,99 & 0,93 & 1,27 & 0,98 & 1,25 & 1,04 & 1,17 & 0,88 \\
\hline Dy ppm & 4,98 & 6,22 & 6,02 & 6,46 & 4,91 & 6,33 & 5,67 & 7,72 & 6,10 & 7,29 & 5,68 & 6,52 & 5,17 \\
\hline $\mathrm{Yb}$ ppm & 2,70 & 3,28 & 3,05 & 3,14 & 2,61 & 3,26 & 3,24 & 3,61 & 3,34 & 3,92 & 2,80 & 3,33 & 2,73 \\
\hline Lu ppm & 0,41 & 0,48 & 0,46 & 0,52 & 0,40 & 0,50 & 0,47 & 0,57 & 0,52 & 0,55 & 0,49 & 0,48 & 0,41 \\
\hline Hf ppm & 6,70 & 6,87 & 6,46 & 7,35 & 5,32 & 7,77 & 6,27 & 7,15 & 8,33 & 5,84 & 6,12 & 7,65 & 6,23 \\
\hline Ta ppm & 1,80 & 1,85 & 1,88 & 1,87 & 1,75 & 1,95 & 1,91 & 1,87 & 1,85 & 1,89 & 1,62 & 1,90 & 1,69 \\
\hline Th ppm & 15,2 & 15,7 & 15,6 & 17,2 & 15,9 & 18,4 & 16,3 & 19,1 & 17,5 & 16,5 & 14,9 & 16,7 & 15,3 \\
\hline U ppm & 1,78 & 2,85 & 2,59 & 2,41 & 4,23 & 4,09 & 3,76 & 3,57 & 4,12 & 3,31 & 2,77 & 3,06 & 3,05 \\
\hline Tm ppm & 044 & 0,52 & 0,47 & 0,49 & 0,41 & 0,56 & 0,52 & 0,57 & 0,52 & 052 & 0,46 & 060 & 0,45 \\
\hline
\end{tabular}


ANEXO 1 - Resultados da análise por activação com neutrões ocontinuação)

\begin{tabular}{|c|c|c|c|c|c|c|c|c|c|c|c|c|}
\hline & L5 & L6 & L7 & L8 & Ml & M2 & M3 & M4 & M5 & M6 & M7 & M8 \\
\hline $20 \%$ & & 0,46 & 64 & 0,41 & 0,36 & 0,39 & 0,41 & 0,60 & 0,67 & 0,69 & 0,41 & 0,59 \\
\hline $0 \%$ & & & & 3,60 & 3,33 & 3,12 & 3,39 & 3,49 & 3,26 & 3,02 & 3,54 & 3,83 \\
\hline $203 \%$ & 5,05 & 5,62 & 6,46 & 5,99 & 4,67 & 6,02 & 6,86 & 5,87 & 4,26 & 4,59 & 7,60 & 7,02 \\
\hline $\mathrm{Sc}$ ppm & 12,3 & 14,8 & 15,3 & 14,4 & 11,5 & 13,5 & 14,5 & & 11,2 & & 16,8 & 16, \\
\hline pm & 59,0 & 67,0 & 68,4 & 62,7 & 59,5 & 63,2 & 64,6 & 62,4 & 54,5 & 63,3 & 76,5 & 75,3 \\
\hline $\mathrm{Mr}$ & 159 & 192 & 181 & 182 & 152 & 151 & 105 & 219 & 157 & 155 & 175 & 224 \\
\hline $\mathrm{CO}$ & 6,96 & 9,62 & 8,24 & 7,66 & 6,24 & 7,27 & 9,81 & 10,10 & 8,49 & 6,81 & 9,62 & 11,5 \\
\hline $\mathrm{Zn} \mathrm{ppm}$ & 75,7 & 96,6 & 83,4 & 88,5 & 62,9 & 78,1 & 59,1 & 95,1 & 79,7 & 67,3 & 99,1 & 94,6 \\
\hline As ppm & 8,30 & 4,93 & 15,30 & 6,08 & 7,89 & 5,72 & 17,50 & 6,61 & 6,18 & 6,94 & 6,95 & 8,07 \\
\hline & 200 & 216 & 213 & 222 & 180 & 186 & $18^{\prime}$ & 221 & 181 & 179 & 218 & 253 \\
\hline $\mathrm{Sb}$ ppm & 0,70 & 0,86 & 0,95 & 0,91 & 0,68 & 0,77 & 1,1 & 0,81 & 0,77 & 0,85 & 0,96 & 1,0 \\
\hline Cs ppm & 12,4 & 14,7 & 15,8 & 15,7 & 12,2 & 12,7 & 13, & 14,0 & 10,6 & 11,8 & 15,2 & 16,3 \\
\hline Ba ppm & 414 & 449 & 467 & 431 & 389 & 475 & 55 & 414 & 410 & 417 & 450 & 492 \\
\hline La ppm & 46,0 & 51,5 & 49,7 & 47,1 & 35,4 & 39,9 & 38,4 & 50,5 & 46,2 & 41,5 & 48,8 & 47,1 \\
\hline & & 100,0 & 89,2 & 91,1 & 72,3 & 80,3 & 77, & 103 & 89 , & 83, & & 93,9 \\
\hline & & 51,1 & 45,3 & 45,7 & 35,9 & 39,8 & 38,3 & 53,5 & 44,8 & 39,7 & 47,3 & 47,0 \\
\hline Sm ppm & 8,51 & 10,40 & 8,89 & 9,14 & 6,94 & 7,57 & 8,00 & 10,60 & 9,11 & 7,42 & 9,60 & 9,32 \\
\hline Eu ppm & 1,35 & 1,72 & 1,59 & 1,54 & 1,25 & 1,33 & 1,30 & 1,84 & 1,56 & 1,15 & 1,76 & 1,70 \\
\hline $\mathrm{Tb} \mathrm{ppm}$ & 1,08 & 1,39 & 1,17 & 1,18 & 0,86 & 1,01 & 1,07 & 1,35 & US & 0,96 & 1,2 & 1,27 \\
\hline Dy ppm & 6,47 & 7,61 & 7,40 & 6,9 & 5,48 & 6,38 & 6,2 & 8,6 & 6,3 & 5,6 & 7,95 & 7,88 \\
\hline & & 4,07 & 3,97 & 3, & 2,8 & 3,31 & & 3,8 & 3,3 & & 4,06 & \\
\hline & & 0,58 & 0,56 & 0,61 & 0,38 & 0,48 & 0,49 & 0,56 & 0,49 & 0,45 & 0,58 & 0,55 \\
\hline Hf ppm & 7,52 & 8,07 & 7,95 & 8,35 & 5,27 & 6,83 & 7,21 & 7,22 & 7,51 & 8,26 & 6,93 & 7,13 \\
\hline Та ppm & 1,92 & 2,17 & 2,16 & 2,03 & 1,48 & 1,92 & 1,98 & 1,96 & 1,93 & 1,81 & 2,47 & 2,12 \\
\hline Th ppm & 18,0 & 18,1 & 19,0 & 18,2 & 13,7 & 17,4 & 17,6 & 18,4 & 16,0 & 19,3 & 19,3 & 18,9 \\
\hline U ppm & & 3,53 & 2,52 & 2,60 & 2,69 & 3,51 & 3,32 & 2,90 & 2,86 & 3,88 & 3,73 & 4,01 \\
\hline Tm ppm & 0,58 & 0,56 & 0,59 & 0,70 & 0,45 & 0,48 & 0,67 & 047 & 0,57 & 0,52 & 0,67 & 0,49 \\
\hline
\end{tabular}

Conimbriga, 32-33 (1993-1994), 191-200 


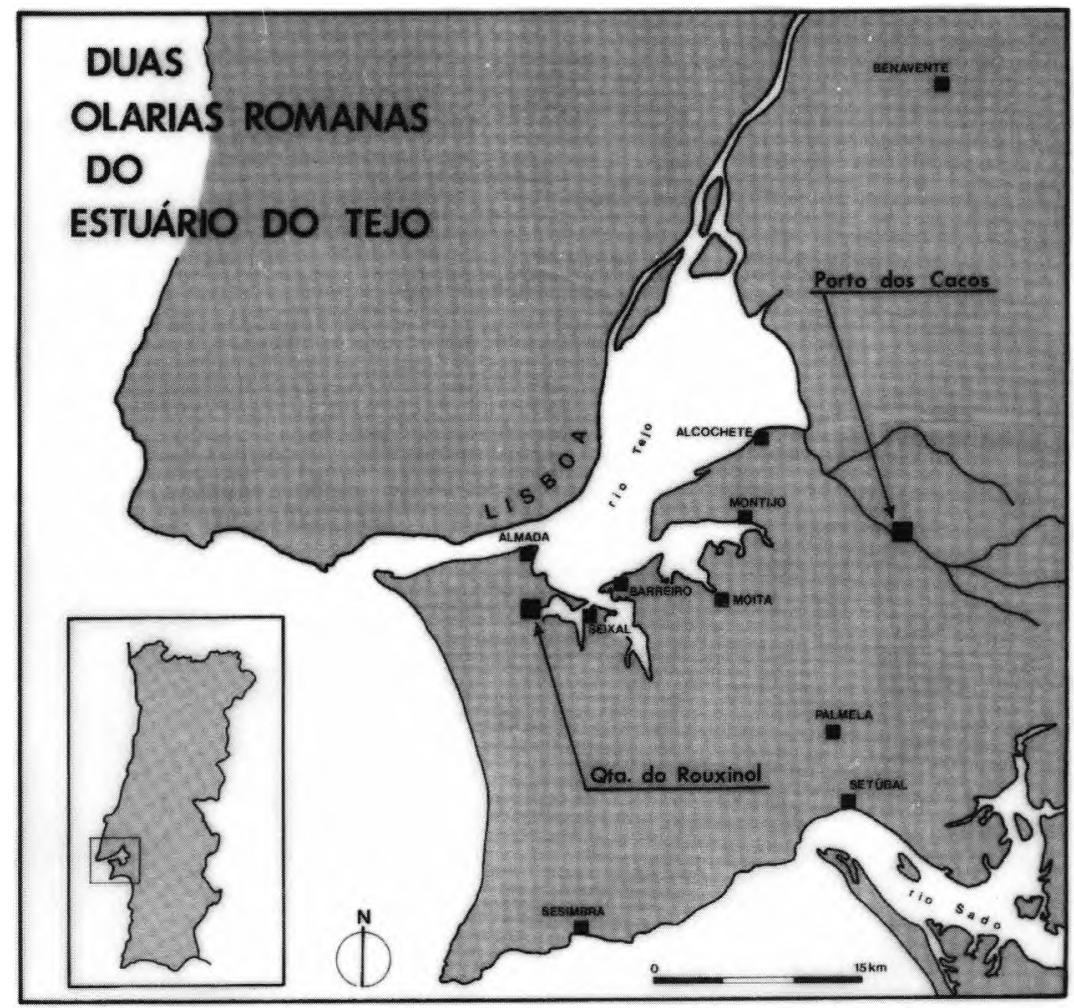

Fig. 1 - Localização da Quinta do Rouxinol. Figura cedida por J. M. C. Raposo. 


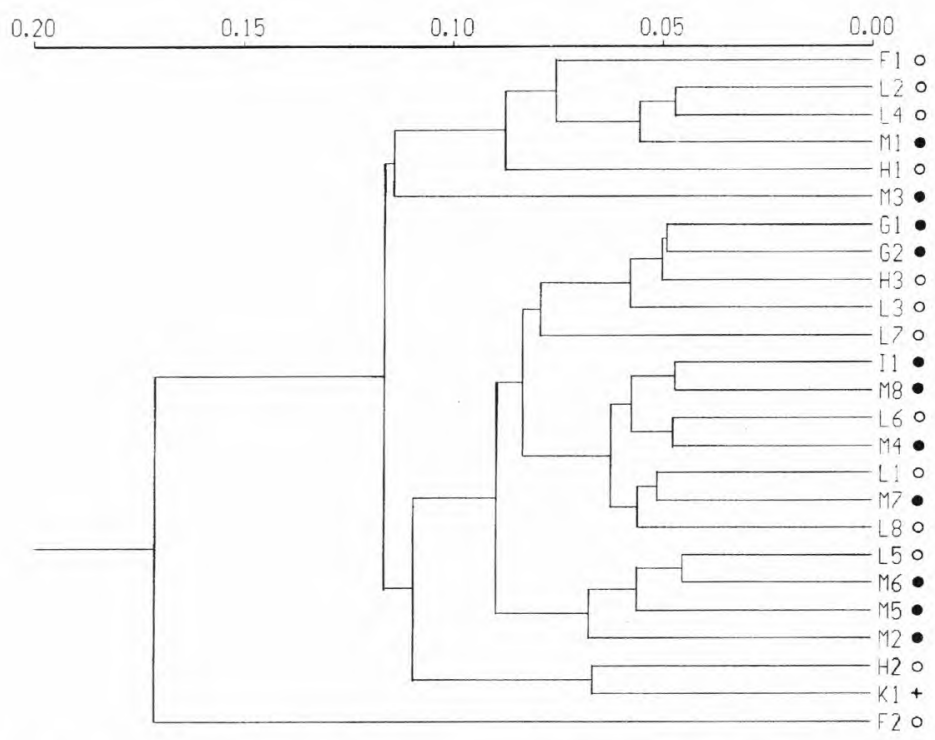

FIG 2 - Dendrograma representativo do agrupamento de 25 ânforas da Quinta do Rouxinol ( Almagro 51c, Almagro 50, $\uparrow$ Dressel 28), obtido caracterizando-as pelas concentrações de 27 elementos, calculando distâncias euclidianas médias e aplicando o método UPGMA.

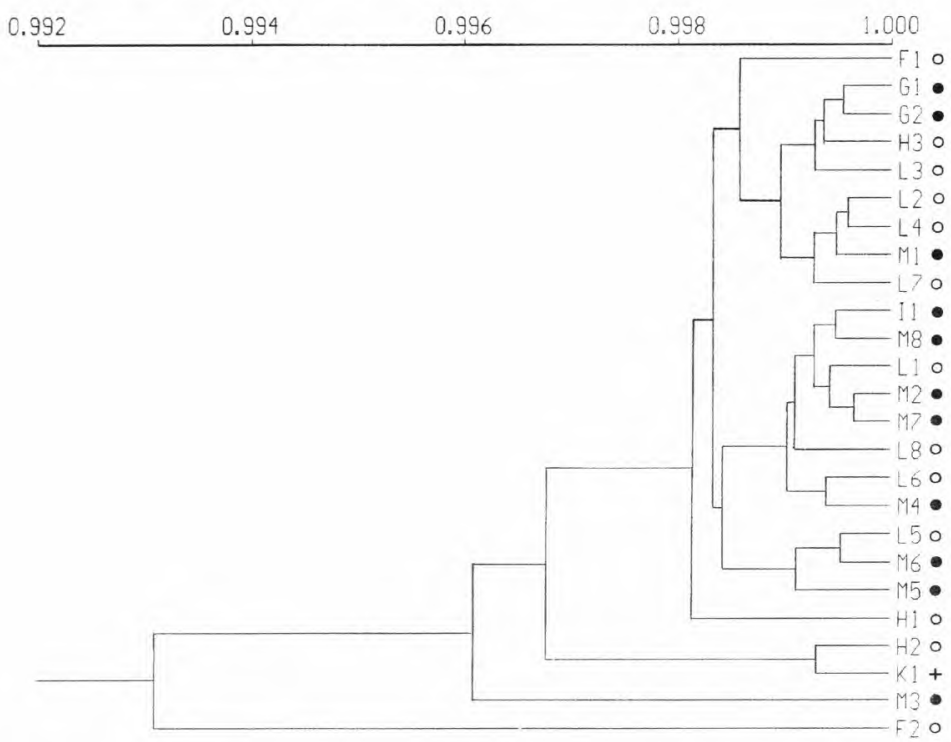

FIG. 3 - Dendrograma representativo do agrupamento de 25 ânforas da Quinta do Rouxinol (O Almagro 51c, * Almagro 50, Dressel 28), cbtido caracterizando-as pelas concentrações de 27 elementos, calculando coeficientes de correlação e aplicando o método UPGMA. 


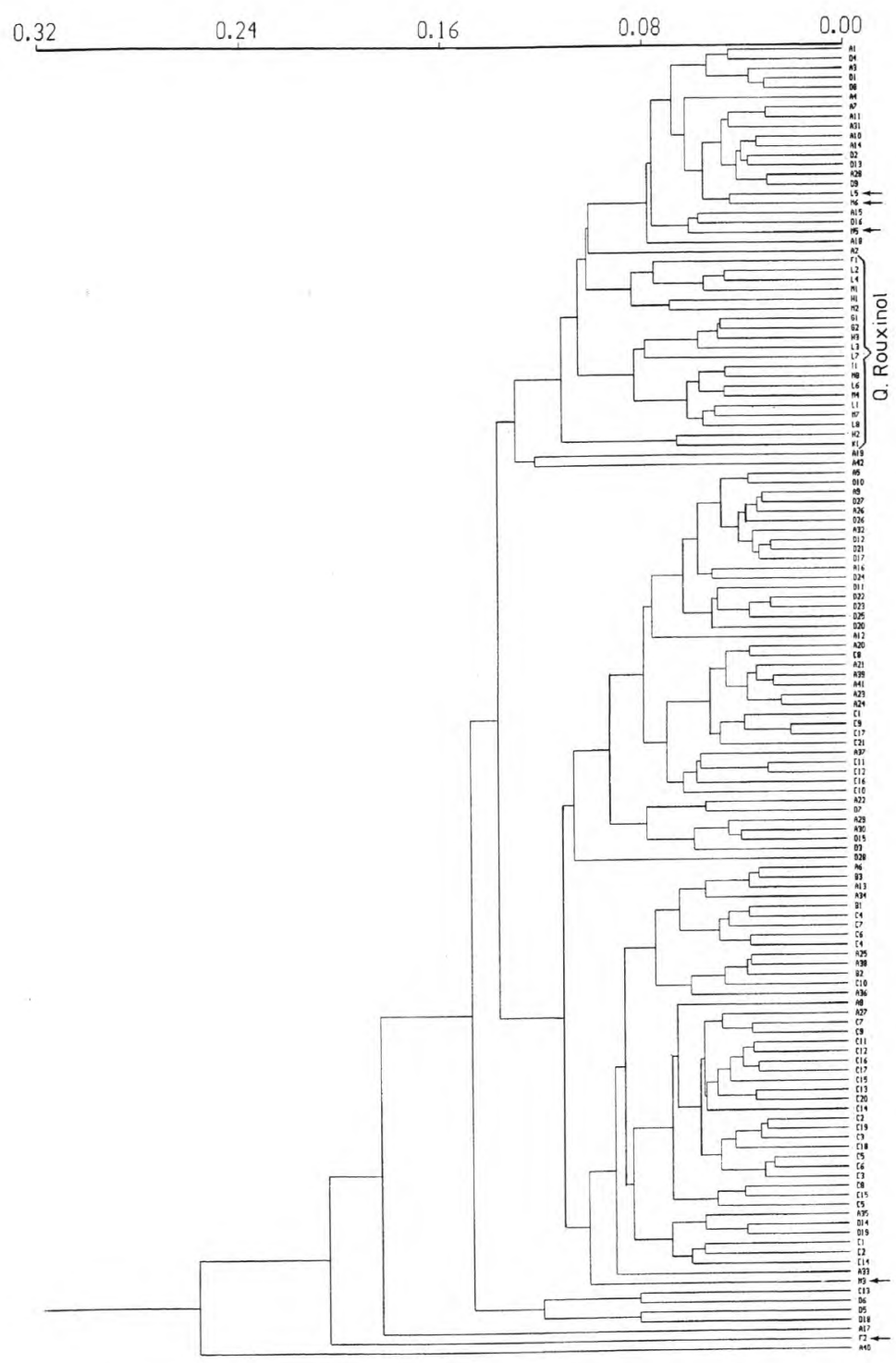

FIG. 4 - Dendrograma representativo do agrupamento de 25 ânforas da Quinta do Rouxinol (indicadas pelo nome ou por setas) mais 111 de Porto dos Cacos (as restantes), obtido caracterizando-as pelas concentrações de 27 elementos, calculando distâncias euclidianas médias e aplicando o método UPGMA. 


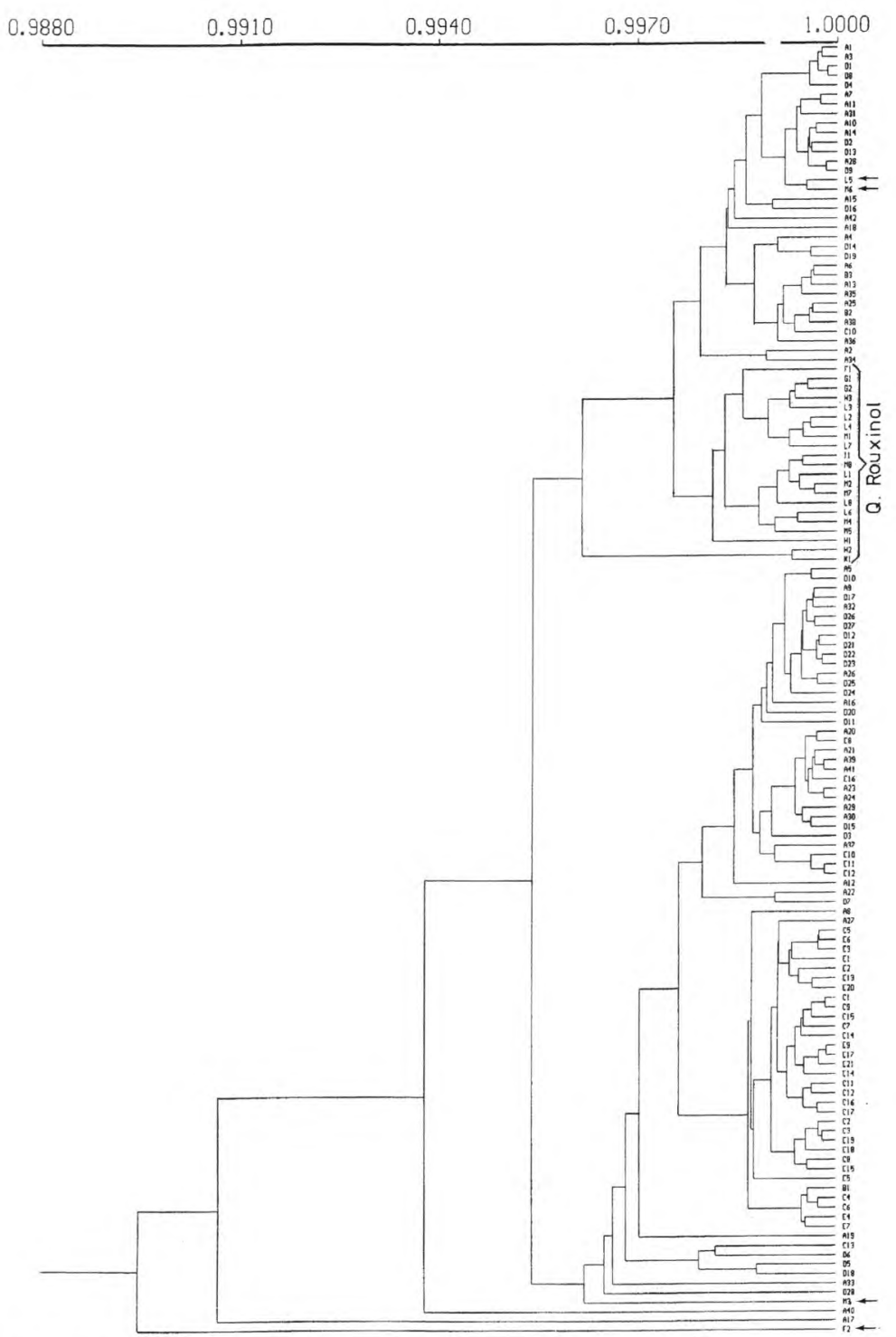

FIG. 5 - Dendrograma representativo do agrupamento de 25 ânforas da Quinta do Rouxinol (indicadas pelo nome ou por setas) mais 111 de Porto dos Cacos (as restantes), obtido caracterizando-as pelas concentrações de 27 elementos, calculando coeficientes de correlação e aplicando o método UPGMA 